\title{
11 ENTERPRISE RESOURCE PLANNING IMPLEMENTATION: STORIES OF POWER, POLITICS, AND RESISTANCE ${ }^{1}$
}

\author{
David Allen \\ Information Systems Institute \\ University of Salford \\ Salford, Manchester M5 4WT \\ United Kingdom \\ Thomas Kern \\ Department of Information and Decision Science \\ Rotterdam School of Management \\ Erasmus University Rotterdam \\ 3000 DR Rotterdam \\ The Netherlands
}

\begin{abstract}
This paper provides an interpretation of information technology implementation in a relatively unexplored context, that of higher education. In recent years, there has been a call by governments across the world for universities to improve operational efficiency and to reduce duplication of resources by implementing advanced information systems that span the institution and improve processes. Universities in response turned their efforts to implementing complex ERP systems to facilitate the essential cross-functional information integration, free internal information flows, and improve the provision and quality of management information. This paper investigates in turn whether enterprise resource planning (ERP) systems present a feasible information system strategy for higher education institutions. Four in-depth case studies were conducted in
\end{abstract}

${ }^{1}$ The authors would like to acknowledge the work of Mark Havenhand, who undertook part of the data collection and analysis as part of his M.Sc. Dissertation.

The original version of this chapter was revised: The copyright line was incorrect. This has been corrected. The Erratum to this chapter is available at DOI: 10.1007/978-0-387-35489-7_33 


\begin{abstract}
higher education institutions (HEIs) that were in the process of implementing ERP systems. Numerous complexities, especially in terms of power, politics, and resistance arose in light of the structure of the HEIs.
\end{abstract}

\title{
1. INTRODUCTION
}

In recent years, government intervention in higher education institutions (HEIs) and the ever increasing demand for education has introduced significant pressure for change on the higher education sector (Ford et al. 1996), while in parallel government funding has been continuously reduced over the years (NCIHE 1997). These factors have been put forward to legitimize changes in the governance (Dearlove 1998) and in the management of higher education institutions (HEIs). It seems that in the last decade, a heady mix of new managerial ideology and new technology has rapidly transformed universities. As IS researchers, we seem almost fatalistic in our view of these changes. As Ives and Jarvenpaa (1996, p. 40) state, "it seems clear that nothing will protect the business school from being swept into the current of technologically driven change... .In fact, the soil is crumbling around us." Yet we seem unwilling to address the interaction between the profound social, organizational, and technological changes which are affecting our organizations. Where we have addressed these issues, we have focused on the area closest to ourselves as academics: the development and implementation of technologies for teaching and learning. The paradox remains that, although much of the expenditure is on management information systems, this rich and significant area for research is, with few exceptions (Heiskanen et al. 1999, 2000; Noble and Newman 1993) largely unexplored by information systems researchers.

This paper attempts to address one facet of this gap in the research and our understanding: the implementation of enterprise resource planning (ERP) systems in UK HEIs. The UK higher education sector spends almost $£ 1$ billion on communication and information technologies each year, representing $10 \%$ of the sector's total turnover (NCIHE 1997). ERP systems were identified by the public sector body that advises on information systems use and implementation in the UK, the Joint Information Systems Committee (JISC), as offering the strategic solution to the different problems HEIs were facing (JISC 1998). These integrated software systems facilitate enterprise resource planning: a method of integrating cross functional information resources to eliminate traditional barriers to communication and provide a seamless flow of information. The arguments supporting ERP implementation in HEIs are indeed seductive. For example, there is the call for simplicity in the complex higher education 
environment for which Fox (1996) suggests integration might be the solution, "making everything appear as one to the user, with a single system interface." Hicks (1997) further brings attention to the inefficiencies and waste caused by the traditional fragmented nature of HEIs, where large numbers of people are essentially duplicating actions and resources. Liang et al. (1998) further corroborate these suggestions, describing how information flows around a university campus are often channeled through disparate sub-systems, resulting in fragmentation and duplication of resources and services. They also propose, in turn, integration and cross-media information services to reduce confusion and waste, arguing in effect for an ERP solution, a proposal further echoed by Gage (1998), who called for an integrated set of applications to allow universities to respond effectively to the rapidly changing environment. During the 1990s, many HEIs implemented ERP systems. In fact, SAP estimated in 1999 that their standard R/3 ERP application suit was being used by over $350 \mathrm{HEIs}$ worldwide. However, in the United Kingdom, HEIs have been particularly slow to embrace ERP technology. Indeed by late 1999, we identified only seven HEIs in the UK out of approximately $200 \mathrm{HEIs}$ that were implementing ERP software (e.g., JD Edwards, Siebel, Oracle, Peoplesoft, or Baan). The market for ERP systems in the private sector seems to be reaching saturation, while in the public sector the market is growing rapidly (Miranda 1999). However, very little published research exists regarding the implementation of ERP systems in this context.

With this governmental backdrop defining the context for ERP implementations in the UK higher education institutions, an urgent study was necessary to understand the implementation issues. The remainder of this paper is structured as follows. The next section outlines the research design for investigating ERP implementations in four higher education institutions in the UK. In section two, we describe the implementation experiences and actors interpretations of the systems. Following the case descriptions (presented in a table format), we provide an analysis of the case studies.

\section{RESEARCH METHODOLOGY}

Since the focus of this research study was to explore enterprise resource planning system implementations, in essence, understanding "how" and "what" impact ERP system will have on HEIs, we pursued an in-depth multiple case study research method. Case research in these types of context has been shown to be particularly appropriate for exploratory research of this nature (Newman and Sabherwal 1996; Walsham 1993). Within case analysis (Waring and Wainwright 2000) and cross case analysis (Holland, Light, and Gibson 1999; 
Holland, Light, and Kawalek 1999) has proved to be particularly effective in analyzing ERP implementations. Two key points were taken into careful consideration to design this research study. First, four of the seven HEIs we knew were currently involved in ERP implementations were contacted for the study. All of them have a university status, thus ensuring that in terms of environment they are all similar in nature. Second, in order to strengthen the generalizability of this study, to produce enough data to investigate ERP implementations and their impact on HEIs, and to provide empirical grounding, we decided to pursue a multiple case studies design (Eisenhardt 1989) comprising four cases. The data collection was undertaken through interviews and reviews of secondary documentation. Seventeen interviews at the four locations of the case study sites in the UK were undertaken. The semi-structured interview protocol was designed to elicit data about the impact of ERP, the risks involved, and the issues involved in ERP implementation management. To maintain confidentiality, the names of the case sites have not been included. The names of respondents have been disguised, their positions have been left out, and the names of the vendors and consultants have been omitted. The authors accept that this will detract from the richness of the case studies, but it was necessary to guarantee the anonymity of all interviewees.

The research took a grounded approach to data analysis. Following Glaser and Strauss's (1967) suggestion, our analysis went through numerous iterations to formulate a coherent and consistent story. With each iteration cyclefollowing the hermeneutic circle principle to case study development (Klein and Myers 1999) - the cases took shape. Interview data was fully transcribed and was analyzed using Atlas-Ti software (Software 1999), following a process of coding and explanation building. This system has been successfully used in cross-case analysis (Marshall et al. 2000) and it facilitates data analysis from the grounded-theory perspective (Dohan and Sanchez-Jankowski 1998). 


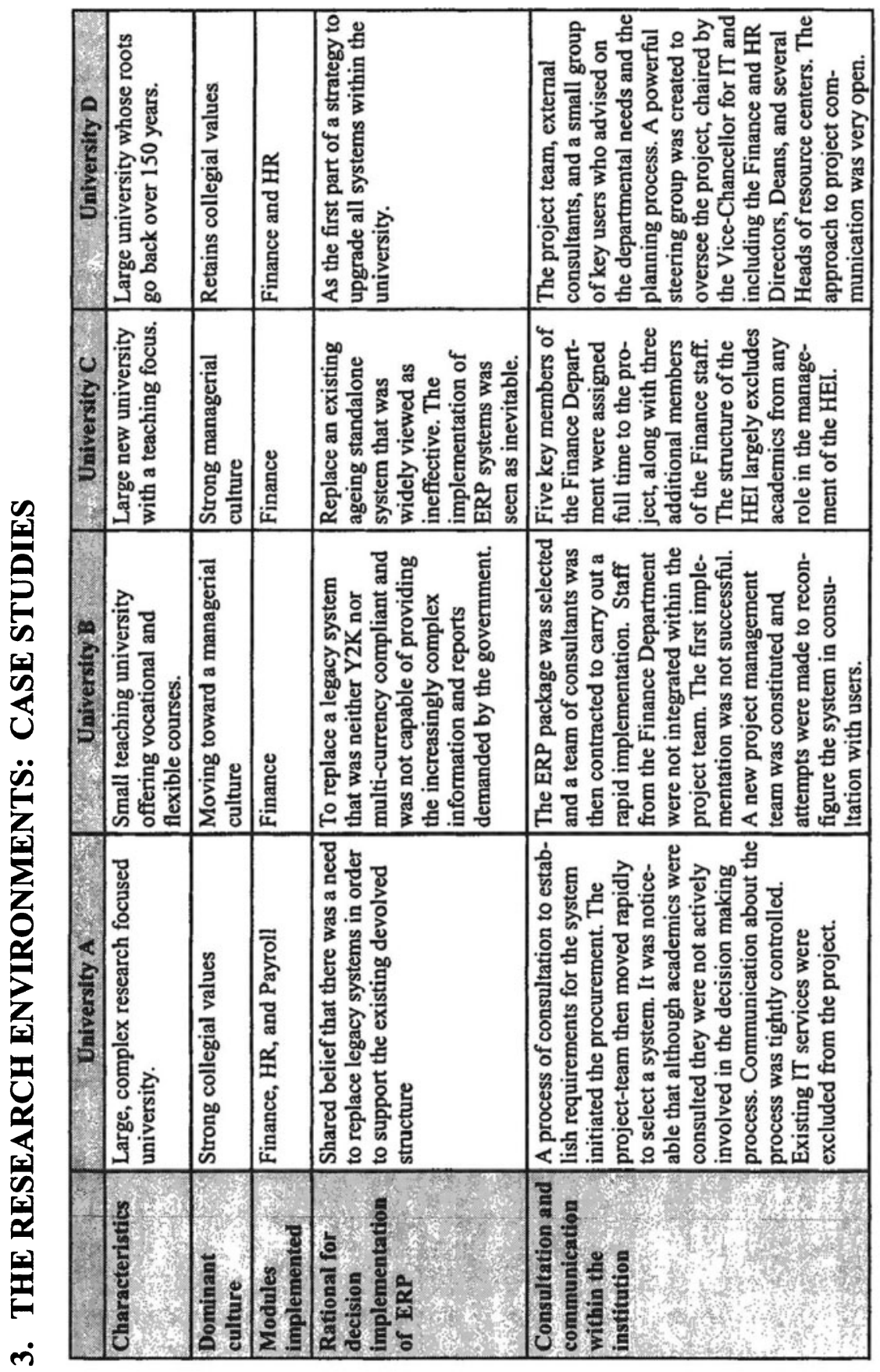




\begin{tabular}{|c|c|c|c|}
\hline$\frac{\vec{z}}{\frac{3}{2}}$ & 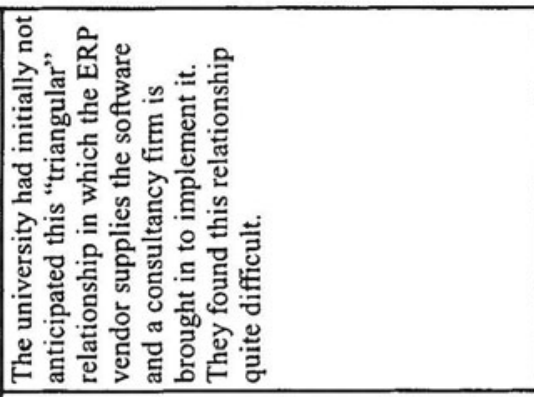 & 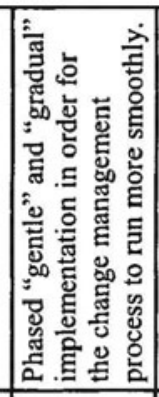 & 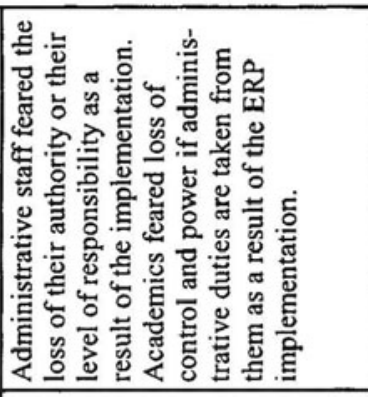 \\
\hline$\frac{U}{3}$ & 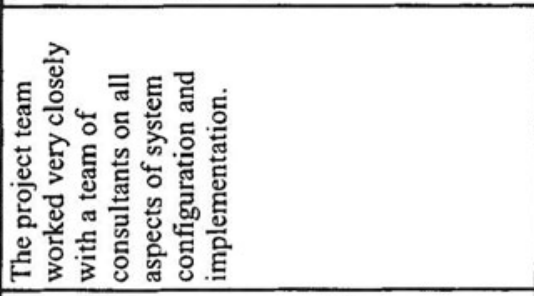 & 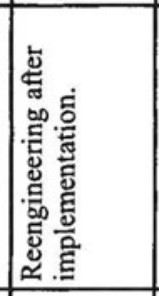 & 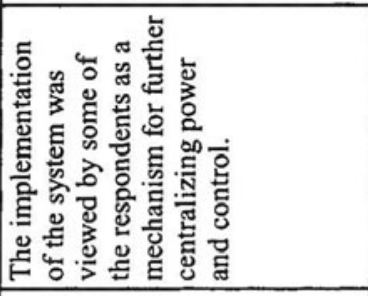 \\
\hline & 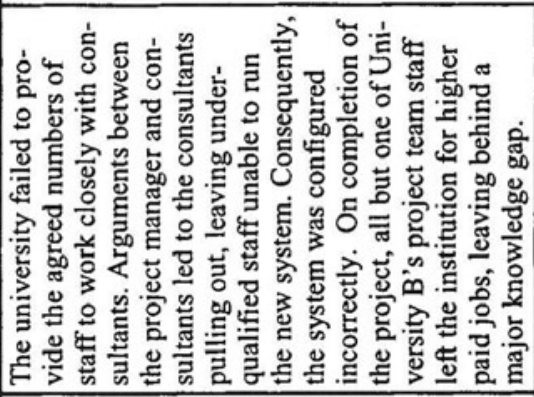 & 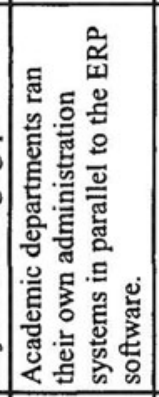 & 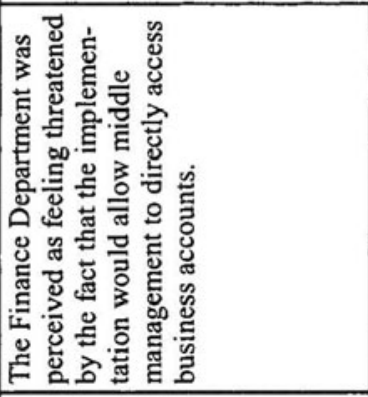 \\
\hline & 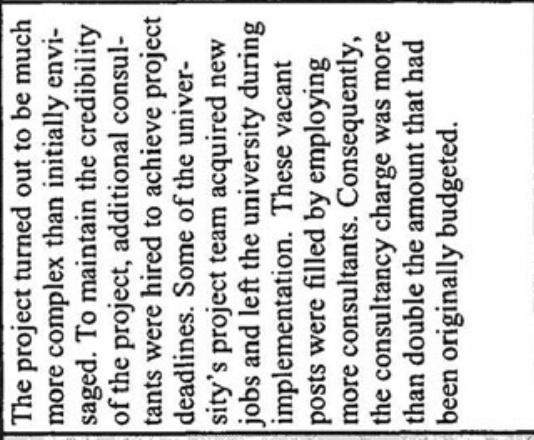 & 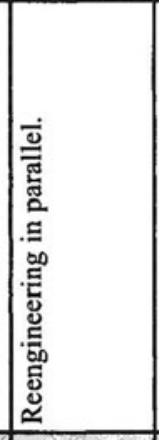 & 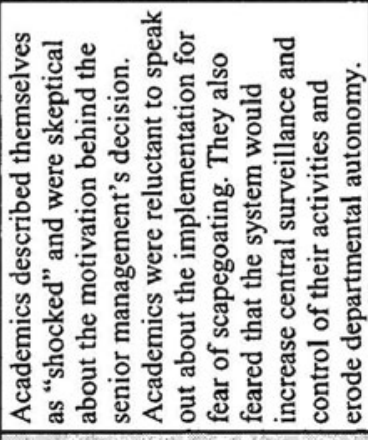 \\
\hline & 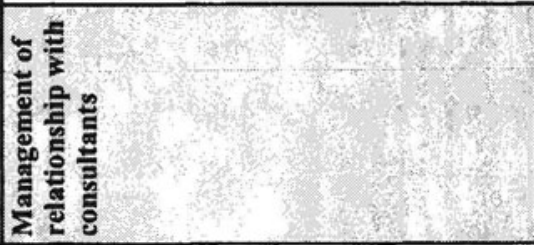 & 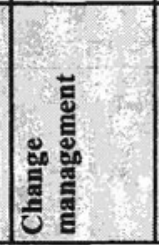 & 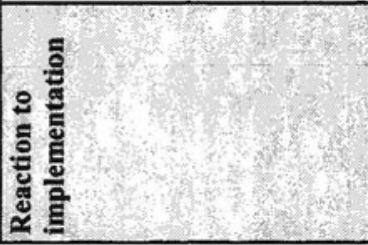 \\
\hline
\end{tabular}




\section{ANALYSIS AND DISCUSSION}

In the following analysis we discuss a set of socially constructed organizational conditions that influence the ERP implementations. It is important at this point to state that when we discuss these conditions, we take an interactionist view point based on the work of Strauss (1993, p. 249): "action is shaped by conditions but in turn is shaped by active actors. Thus, one can say yes, there definitely is social structure, but it is not immutable, totally unshapable, and certainly not entirely determining of action."

In the four case studies, we found that organizational culture had a significant impact on the implementation. An ERP application is more than just an information system or computer software; it is a business philosophy based on private sector "best business/process practice" (Hiquet 1998). It brings with it the ideologies of the private sector. The implementation of the ERP systems and process reengineering can be seen as attempts to change organizational culture at the level of ideology, norms, and meanings. To the extent these ideologies, norms and meanings are internalized, people accept and thereby reproduce the invented definition of reality (Knights and Willmott 1999). These have been described as the "hidden structures of power" (Thompson and McHugh 1995, p. 137) or "deep structures" (Clegg 1994; Conrad 1983). They provide socially validated ways of interpreting, judging, and reacting (Conrad 1983). In our study, the technology was seen as a managerial Trojan horse, which would transform work practices and culture to those of a private sector organization. It was seen as a weapon in the ideological struggle between the forces of managerialism and academia, with academics struggling to maintain cultural values which reflect their relational and collegiate forms of working (Clark et al. 1997), attempting to retain values such as those of academic freedom and autonomy. In our study, the clash of academic and managerial ideologies was explicitly understood by the actors within the universities, as one respondent stated:

I doubt you'll find anybody who'll readily admit they are a business. They'll say "we're not a business, we're a university," we don't make profits but we have a surplus at the end of the year. They're very culturally different to anything I've ever met in industry (Respondent 13, lines 38:43, University B).

While the implementers in some institutions perceived academic culture as a negative phenomena (as illustrated by the following quotation), their actions were also bounded by it: 
They [academics] don't care about getting a bit more budget all they're bothered about is this academic freedom, that says I can do what I want, when I want, without anybody telling me how to do it (Respondent 13, lines 222:225, University B).

Academic culture was invariably seen as a barrier to the implementation and "strength" of the culture was perceived as dictating the approach taken to organizational redesign. Thus, for example, in University C, an attempt was made to modify the code, a solution that the systems developers saw as unsatisfactory yet as inevitable given the organizational context within which they were working. While almost invariably implementers described their approach as more and "logical," "effective," and "rational," for many within the institution the implementation of the systems and the concomitant reengineering were deeply threatening and perceived as heralding new power relations.

Cultural resistance in University D was underpinned and in part explained by the perception that the implementation of the system would support a particular political agenda. In many older institutions, such as $\mathrm{D}$ and $\mathrm{A}$, the decisionmaking structures were designed on a democratic, participative, consultative, and collective model. As the universities grew in size and complexity, professional bureaucracies were introduced to perform an administrative role. These new administrative structures were, therefore, overlaid on the existing collegial structures based on academic self-governance. Resistance to the implementation of ERP systems in this situation can be explained as being predicated on the belief that the implementation would reinforce a model of governance based on administrative authority. A respondent in University A stated:

There is no example of a university where the academic staff are heavily controlled, which is regarded as being a good university. (Respondent 1 , lines 406:408, University A).

While the change brought about as a result of the ERP projects has devolved a certain amount of power out to departments, it has enforced the adoption of centrally designed practices and procedures:

Devolution sounds like liberalization, but the center places all kinds of demands for feedback of information so they can monitor what is going on and put ever new procedures and regulations. But then the responsibility for the failure of these remains with the departments (Respondent 1, lines 188:192, University A). 
One respondent described the ERP software as a method of pretending to give devolution while keeping an "iron grip" on processes. The main opposition from departments concerned the phasing out of their own mini systems, which many department heads felt had better functionality than the new ERP system (Respondent 14, 17, University D). The view of Parker and Jary (1995, p. 327) seems to encapsulate the fears of these respondents: "it is less convincing to talk about a university as a community of scholars; perhaps instead it is a legally constituted corporate surveillance mechanism."

In common with the craft or manual workers in Zuboff's (1988) study, these academics feared the use of this information technology could render their actions as transparent to senior management. They feared that senior managers would not only be able to use the information to satisfy their need for additional certainty and control, but would also use it to inscribe academic behavior. In short, they viewed the implementation of the technology as creating an information panoptican.

In University C, in contrast, the culture of the university was in many ways already that of a business. As a post-1992 university, it was a corporation and its governance structures and management style in many ways already reflected that of a private sector organization. Power was centralized in the hands of a chief executive and his senior management team. The downgrading of academic structures such as the academic board had already taken place. While some interviewees were fearful of the implications of the implementation, they had already been disenfranchised and, therefore, had less opportunity to act. The implementation of ERP software in this environment merely reinforced the status quo.

While the academics feared loss of control, the reaction of the administrative staff who were using the existing systems in the sites was to fear for their jobs. Management in University D and University A attempted to allay these fears by stating that the project would not lead to redundancies, but would lead to some redeployment of personnel. The result of this approach was, however, to increase multi-dimensional job insecurity (Burchell et al. 1999) as employees feared that they might lose responsibility and authority. The users were worried about their job security, their position, their authority, and the effect of the new system on their everyday work:

So there's a certain amount of job insecurity, unjustified in terms of whether they are going to have a job or not (Respondent 14, lines 240:242, University D).

Respondents at University C, on the other hand, felt that job losses were inevitable: 
It's an expensive system and that's the only way you can sell it to the university, that it will take less staff to run (Respondent 10, lines 176:178, University C).

Recent work by Sarker and Lee (2000) indicates that open and honest communication (while possibly helpful) is not a necessary condition for ERP implementation. We would refute this finding and argue that it is, perhaps, one of the most important. In our study, the universities took very different approaches to communication. In University A, users believed that, to control opposition to the ERP project, the project team and senior managers tightly control information circulated on the project. One respondent stated that this effectively controlled the opinions of academics:

So all that has to be done is that information just has to be delayed or kept incomplete and they feel unable to comment, they say we'll have to wait and see how it works out. So there isn't really any resistance (Respondent 1, lines 288:291, University A).

However, while this initially achieved the desired effect, it then caused other problems. It encouraged the spread of half-truths and rumors about the project (Respondent 17) and led to a consensus in the university that the project was a failure (Respondent 16). As Jones (1991, p. 143) notes, "the earliest hint of changes in organizational arrangements seems likely to arouse activity which influences the ultimate acceptability of the proposals." Communication using inhouse magazines seemed to be counter productive. Indeed, respondent felt bombarded by "project propaganda in the glossy university magazines and bulletins, while circulating rumors talk of escalating costs and problems":

Official news speaks of how lucky University A is to be implementing such a wonderful information system, while academics and staff hear about less qualified consultants being paid hundreds of pounds a day, to bend the "inflexible" ERP software to fit their university (Respondent 1, University A).

On the other hand, University D took an extremely open attitude to communication, arguing the case for the ERP project through numerous committees and meetings (Respondent 16, University D). They felt that by "laying all the cards on the table," the change process was a relatively smooth one. At University $D$, despite complaints about the user-friendliness of the ERP, there is an organization-wide understanding of the project's purpose and perhaps a little more tolerance. 
A final issue was that of relationship and knowledge management. Preliminary results survey research undertaken by Chang et al. (2000) indicate that this is the most problematic area for ERP implementation in the public sector. In our research, we found that the purchase of a ERP system brings a university into a complex implementation relationship with the ERP vendor and an implementation/consultation partner. It seems clear that the internal information systems staff play an essential role in, as Butler and Fitzgerald (1999) state, the weaving of technology into the social fabric of the organization.

\section{CONCLUSION}

In this short paper, we have presented our re-interpretation of the issues that influence ERP implementation. In particular we identify organizational culture, constructions of past technological implementations, relationship and knowledge management, and the existing power structures within the organization as key issues. We emphasize the need for a "reappraisal and further investigation of the multifaceted political dimension of change agency, and the complex and tacit nature of the skills involved" (Buchanan and Badham 1999).

The higher education institutions in which we work are fundamentally changing. Much of this change is legitimized by new managerial discourses and technologies. To date, organizational theorists have discussed the introduction of new managerial style and techniques (Willmott 1995) and educational theorists have questioned the impact of new instructional technologies (Noble 1998). Researchers in the field of information systems, however, have remained unusually bashful in contributing to this debate. It seems paradoxical to the authors that members of our community seem more than willing to discuss these issues in the context of, for example, health care (Bloomfield et al. 1997; Doolin and Lawrence 1997, Jones 1994), while we seem noticeably reluctant to theorize about our own work organizations.

\section{REFERENCES}

Bloomfield, B. P., Coombs, R., Knights, D., and Littler, D. A. (eds.). Information Technology and Organizations Strategies Networks and Integration, Oxford: Oxford University, 1997.

Buchanan, D., and Badham, R. "Politics and Organizational Change: The Lived Experience," Human Relations (52:5), 1999, pp. 609-624

Burchell, B. J., Day, D., Hudson, M., Ladipo, D., Mankelow, R., Nolan, J. P., Reed, H., Wichert, I. C., and Wilkinson, F. Job Insecurity and Work Intensification: Flexibility and the Changing Boundaries of Work, York, UK: York Publishing Services (for the Joseph Rountree Foundation), 1999.

Butler, T., and Fitzgerald, B. "Enterprise Transformation and the Alignment of Business and Information Technology Strategies: Lessons from Practice," in Information Systems: Current 
Issues and Future Changes, T. J. Larsen, L. Levine, and J. I. DeGross (eds.), Laxenburg, Austria: IFIP Press, 1999.

Chang, S. I., Gable, G., Smythe, E., and Timbrell, G. "A Delphi Examination of Public Sector ERP Implementation Issues," in Proceedings of the Twenty-First International Conference on Information Systems, W. J. Orlikowski, S. Ang, P. Weill, H. C. Krcmar, and J. I. DeGross (eds.), Brisbane, Australia, December 2000.

Clark, H., Chandler, J., and Barry, J. "For a Moment We See Ourselves as Puppets Indeed: MANagement and Higher Education in Britain," paper delivered at the Standing Conference on Organisational Symbolism (SCOS), Fifteenth International Conference, "The Empty Space," Academy of Entrepreneurship and Management, Warsaw, 1997.

Clegg, S. R. Frameworks of Power, London: Sage, 1994.

Conrad, C. "Organizational Power: Faces and Symbolic Forms," in Communication and Organization: An Interpretive Approach, L. I Putnam and M. E Paconowsky (eds.), Beverly Hills, CA: Sage, 1983, pp. 173-194.

Dearlove, J. "Fundamental Changes in Institutional Governance Structures: The United Kingdom," Higher Education Policy (11), 1998, pp. 111-120.

Dohan, D., and Sanchez-Jankowski, M. "Using Computers to Analyze Ethnographic Field Data: Theoretical and Practical Considerations," Annual Review of Sociology (22:1), 1998, pp. 477499.

Doolin, B., and Lawrence, S. "Managerialism, Information Technology and Health Reform in New Zealand," International Journal of Public Sector Management (10:1/2), 1997, pp. 108122.

Eisenhardt, K. "Building Theory from Case Study Research," Academy of Management Review (14:4), 1989, pp. 532-550.

Ford, P., Goodyear, P., Heseltine, R., Lewis, R., Darby, J., Graves, J., Sartorius, P., Harwood, D., and King, T. Managing Change in Higher Education, Buckingham: SRHE \& Open University Press, 1996.

Fox, K. C. "Information Technology in Higher Education: Evolving Learning Environments," Educause, 1996 (available from http://www.Educause.edu/ir/library/pdf/CMR9823.pdf).

Gage, J. F. "Making Peoplesoft Administrative Systems Work," Educause, 1998 (available from http://www.Educause.edu/ir/library/html/cnc9862/cnc9862.html).

Glaser, B. G., and Strauss, A. L. The Discovery of Grounded Theory: Strategies for Qualitative Researchm: Chicago: Aldine De Gruyter, 1967.

Heiskanen, A., Newman, M., and Saarinen, V. "Innovations in Fiefdoms: Developing a Common Student Information System in Six Finnish Universities," in Information Systems: Current Issues and Future Changes, T. J. Larsen, L. Levine, and J. I. DeGross (eds.), Laxenburg, Austria: IFIP Press, 1999.

Heiskanen, A., Newman, M., and Similä, J. "The Social Dynamics of Software Development," Accounting, Management and Information Technologies (10:1), 2000, pp. 1-32.

Hicks, P. J. "Re-engineering Higher Education," Unpublished Discussion Paper, UMIST, 1997,

Hiquet, B. D. SAP R/3 Implementation Guide, Indianapolis, IN: Macmillan Technical Publishing, 1998.

Holland, C. P., Light, B., and Gibson, N. "A Critical Success Factors Model for Enterprise Resource Planing Implementation," in Proceedings of the Seventh European Conference on Information Systems, J. Pries-Heje, C. Ciborra, K. Kautz, J. Valor, D. Avison, and C. Heje (eds.), Copenhagen Business School, Copenhagen, Denmark, June 23-25, 1999, pp. $273-287$.

Holland, C. P., Light, B., and Kawalek, P. "Beyond Enterprise Resource Planning Projects: Innovative Strategies for Competitive Advantage," in Proceedings of the Seventh European Conference on Information Systems, J. Pries-Heje, C. Ciborra, K. Kautz, J. Valor, D. Avison, and C. Heje (eds.), Copenhagen Business School, Copenhagen, Denmark, June 23-25, 1999, 288-301. 
Ives, B., and Jarvenpaa, S. L. "Will the Internet Revolutionize Business Education and Research?" Sloan Management Review (37:3), 1996, pp. 33-41.

JISC. "The C\&IT Aware Manager," Joint Information Systems Committee, 1998 (available from http://www.jisc.ac.uk/pub98/assist5.html).

Jones, C. S. "Power, Politics and the Jarratt Proposals for Accounting in British Universities," Financial Accounting and Management (7:3), 1991, pp. 143-158.

Jones, M. R. "Learning the Language of the Market: Information Systems Strategy Formulation in a UK District Health Authority," Accounting, Management and Information Technology (4:3), 1994, pp. 119-147.

Klein, H. K., and Myers, M. D. "A Set of Principles for Conducting and Evaluating Interpretive Field Studies in Information Systems," MIS Quarterly (23:1), 1999, pp. 67-80

Knights, D., and Willmott, H. Management Lives: Power and Identity in Work Organizations, London: Sage, 1999.

Liang, C. C., Cheng, F., and Wang, E. H. "Reengineering University Information Services: Yuan Ze University's Experience," CAUSE/EFFECT Journal (21:4), 1998 (available from http://www.educause.edu/ir/library/html/cem9848.html).

Marshall, V., Wilson, T. D., Marshall, J. G., and Harris, R. "Plus ca change, plus c'est different: A Report from the KALIPER Project on Six Ccase Studies in LIS Education," in Proceedings of the ALISE 2000 Annual Conference, San Antonio, Texas, 2000 (available from http://www.alise.org/nondiscuss/conf00_Victoria_Marshall_Plus.htm).

Miranda, R. "The Rise of ERP Technology in the Public Sector," Government Finance Review (15:4), 1999, pp. 9-29.

NCIHE. Higher Education in the Learning Society, (R. Dearing, Chair), National Committee of Inquiry into Higher Education., 1997 (available from http://www.leeds.ac.uk/educol/ ncihe/index.htm).

Newman, M., and Sabherwal, R. "Determinants of Commitment to Information Systems Development: A Longitudinal Investigation," MIS Quarterly (20:1), 1996, pp. 23-55.

Noble, D. F. "Digital Diploma Mills: The Automation of Higher Education," First Monday (3:1), January 5, 1998 (available from http://www.firstmonday.dk/issues/issue3_1/noble/ index.html).

Noble, F., and Newman, M. "Integrated System, Autonomous Departments: Organizational Invalidity and System Change in a University," Journal of Management Studies (30:2), 1993, pp. 195-217.

Parker, M., and Jary, D. "The McUniversity: Organization, Management and Academic Subjectivity," Organization (2:1), 1995, pp. 319-339.

Sarker, S., and Lee, A. S. "Using a Case Study to Test the Role of Three Key Social Enablers in ERP Implementation," in Proceedings of the Twenty-First International Conference on Information Systems, W. J. Orlikowski, S. Ang, P. Weill, H. C. Krcmar, and J. I. DeGross (eds.), Brisbane, Australia, December 2000.

Software. ATLAS:ti 4.1 Build 55, London: Sage Publications Ltd., 1999.

Strauss, A. Continual Permutations of Action, New York: Aldine De Gruyter, 1993.

Thompson, P., and McHugh, D. Work Organizations: A Critical Introduction," Basingstoke, England: Macmillan Press Ltd., 1995.

Walsham, G. Interpreting Information Systems in Organizations, Chichester, England: John Wiley \& Sons, 1993.

Waring, T. S., and Wainwright, D. "Integrated Information Systems: Rhetoric and Reality," paper presented at the Fifth United Kingdom Academy for Information Systems Conference, University of Wales, Cardiff, United Kingdom, April 26-28, 2000.

Willmott, H. "Managing the Academics: Commodification and Control in the Development of University Education in the U.K.," Human Relations (48:9), 1995, pp. 993-1028. 
Zuboff, S. In the Age of the Smart Machine: The Future of Work and Power, New York: Basic Books Inc, 1988.

\section{About the Authors}

Thomas Kern is assistant professor for information management at the Rotterdam School of Management. His research interest are IT outsourcing, IT strategy and relationship management. He received his D.Phil. Management Information Systems from Christ Church, University of Oxford. He is also a research affiliate with the Oxford Institute of Information Management at Templeton College and currently the European editor of Journal of Information Technology. He has published papers at the European and International Conferences on Information Systems and in the European Journal of Information Systems, Journal of Information Systems, Journal of Information Strategic Systems, Journal of Global Information Management, and Journal of Information Technology. He is co-author of the book The Relationship Advantage: Sourcing, Technologies, and Management (Oxford University Press, forthcoming 2001) and Application Service Provision: Sourcing Strategies (PrenticeHall, forthcoming 2001). He can be reached by e-mail at tkern@fbk.eur.nl.

David Allen is a lecturer in the Information Systems Institute at Salford University. His research deals with information systems and their implications for work and organization, particularly at the strategic level. He also has an interest in the current discourse about the socio- philosophical foundations of information systems and information management. He has published widely in these areas, with recent papers in the Journal of the American Society for Information Science, International Journal of Information Management, and Journal of Information Systems. He can be reached by e-mail at d.k.allen@ salford.ac.uk. 